\title{
LOS DERECHOS HUMANOS ANTE LAS AMENAZAS DE LAS DEMOCRACIAS DELEGATIVAS. UNA APROXIMACIÓN A LOS CASOS DE VENEZUELA, NICARAGUA Y ECUADOR
}

\author{
HUMAN RIGHTS THREATEN BY DELEGATIVE DEMOCRACIES. AN \\ APPROACH TO VENEZUELA, NICARAGUA AND ECUADOR
}

\author{
Andrés Martínez Moscoso \\ Manuel Francisco Ruiz Guerrero \\ Universidad de Alicante. España/Spain \\ famm3@alu.ua.es \\ mruiz.guerrero@ua.es
}

Recibido/Received: 27/03/2014

Modificado/Modified: 30/05/2014

Aceptado/Accepted: 27/06/2014

\section{RESUMEN}

El estudio explica la importancia que ha tenido, en los procesos de transición democrática, la constitucionalización de los derechos humanos consagrados en la Convención Americana, conocida como "Pacto de San José". Nuestro análisis destaca, que los países de Venezuela, Nicaragua y Ecuador, en su proceso de consolidación democrática establecen, en su ley fundamental, la protección de los derechos políticos que aseguran la participación de las personas en la construcción del nuevo Estado. Se efectúa además, un recorrido doctrinal sobre los conceptos y las tipologías de democracias. Se analizan los riesgos de las democracias delegativas, en los países de Venezuela, Nicaragua y Ecuador, así como la necesidad de incrementar los niveles de institucionalidad democrática para la correcta garantía y aplicación de los Derechos Fundamentales consagrados en sus constituciones.

\section{PALABRAS CLAVE}

Constitución, Derechos Humanos, Estado de derecho, Latinoamérica, democracia delegativa, Venezuela, Nicaragua, Ecuador.

\section{SUMARIO}

1. Introducción. 2. Definición conceptual de los tipos de democracia. 3. El estado puro de la democracia. La democracia directa. 4. La democracia representativa. 5. Los mecanismos de participación y la democracia participativa. 6. Postulados y garantías mínimas. 7. Los riesgos en América Latina de la democracia delegativa. 8. Los casos de Venezuela, Nicaragua y Ecuador ante la necesidad de generar gobiernos democráticos. 9. La imposibilidad de un retroceso frente a la necesidad de mayor institucionalidad. 10. Los retos de la democracia latinoamericana y los derechos humamos como factor de cohesión. 11. Algunas reflexiones finales. Bibliografía.

\footnotetext{
ABSTRACT

This study frames the importance of Human Rights Constitution development in the process of democratic transition agreed in the American convention of San Jose's pact. Our analysis highlights the protection of political rights stated by Venezuela, Nicaragua and Ecuador in their democratic process to ensure the participation of characters in the development of a new State. The condition to increase the
} 
levels of democratic institutional framework to achieve the correct application of Fundamental Rights and the risks of delegative democracies in Nicaragua, Venezuela and Ecuador, were defined in this document through an extensive analysis of definitions and typologies of democratic systems.

\section{KEYWORDS}

Constitution, Human Rights, rule of law, Latin America, delegative democracy, Venezuela, Nicaragua, Ecuador.

\section{CONTENTS}

1. Introduction. 2. Conceptual definition. Types of democracy. 3. Pure democracy. Direct democracy. 4. Representative democracy. 5. Public participation mechanisms and participatory democracy. 6. Requirements and minimum guarantees. 7. Risks for democratic rule in Latin America: delegative democracy. 8. Venezuela, Nicaragua and Ecuador cases and the necessity to generate democratic governments. 9. No regression and the requirement of more institutional conditions. 10. Latin America democracy challenges and human rights as a factor of cohesion. 11. Some final reflections. References.

\section{INTRODUCCIÓN}

La democracia ha sido tradicionalmente una de las instituciones más estudiadas por politólogos, sociólogos y juristas, y sus aportaciones doctrinales han generado una teoría consolidada sobre los conceptos y los tipos de democracias.

El presente estudio aborda la situación pura de la democracia, destacando los elementos de la democracia directa, representativa y participaba y cómo estos han reivindicado el papel del ciudadano como sujeto activo y pasivo. Se realiza además una crítica sustancial a la corriente actual, que sostiene que sería mejor volver a los orígenes donde todos podamos participar en la toma de las decisiones de la polis, para lo cual se usa un ejemplo desarrollado a partir de las TIC.

Se discute también acerca de la configuración de la democracia delegativa, y los riesgos que esta tiene en las repúblicas presidencialistas, donde la confusión persistente radica en que quien resulta electo por la mayoría cree que dicho apoyo traducido en votos, le da una carta en blanco para administrar el Estado sin responsabilidad alguna derivada de sus actos. En éstas líneas que abordan este estudio se demuestra que es una concepción equivoca. El límite a los poderes del ejecutivo y legislativo, se enmarcan a nivel latinoamericano en los preceptos de la Convención Americana de Derechos Humanos, su sistema y la constitucionalización de aquellos en las normas fundamentales de cada uno de los Estados.

A la luz de los aportes académicos sobre las doctrinas de las democracias, se aplican a los casos de Venezuela, Nicaragua y Ecuador, países pocos estudiados de manera grupal, pero que a la fecha reúnen una importancia práctica ya que comparten rasgos comunes en su proyecto político e ideológico, en el contexto actual del continente iberoamericano.

Se efectúa también un recorrido histórico del proceso de consolidación democrática de los países objeto de estudio. Se analiza asimismo brevemente la nueva geometría del poder en Venezuela, la configuración de la democracia directa y la crisis institucional en Nicaragua; y seguidamente se expone la crisis de la representación de Ecuador (partidos y la partidocracia) en el proyecto de la autodenominada "Revolución Ciudadana".

Finalmente se destacan, las metas que deben cumplir cada uno de estos países para alcanzar mayores niveles de institucionalidad, en donde la promoción y protección de los Derechos Humanos sea el principal baluarte y eje central del poder político. 


\section{DEFINICIÓN CONCEPTUAL DE LOS TIPOS DE DEMOCRACIA}

Giovanni Sartori, considera que no es posible discutir sobre "la palabra" ignorando "la cosa". Es por ello que aunque parezca obvio, es necesario realizar una aproximación al término griego demokratia, que como sabemos encarna dos conceptos poderosos: pueblo y poder, situación que de ser categóricamente cierta significaría que los miembros de la comunidad mandarían. Esto mismo fue, lo que pensaron los griegos, quienes a la palabra "demos" le asignaron más de un significado: plethos (el pleno de ciudadanos); hoi polloi (muchos); hoi pleiones (los más, que a criterio de Sartori este será el término que se desarrollará para entender a la democracia como la concebimos en la actualidad); y por último, ochlos (multitud) (Sartori, 2009:16).

Pese a ello, entre otros autores como, José Antonio Marina (2011:57-58), sostiene, que a diferencia del resto de culturas, para el mundo occidental fue una ventaja la manera mediante la cual los atenienses encontraron en la democracia la forma opuesta a la esclavitud y el sometimiento. Ahí radica la importancia de la libertad como modo de vivir; sin generar excesos que lleven a la anarquía y, para ello vieron la existencia de las leyes. Conquista que sostenían y que incluso estaban dispuestos a defenderla con su vida. Este autor también señala que quien fue el verdadero padre de la democracia griega, fue Clístenes, el cual basó su descubrimiento en la "isonomía", que es la igualdad ante la ley, y que vendría a ser la piedra angular la que realmente descansa la construcción de la democracia.

Frente a esto encontramos en la obra de González y Quesada (1992) una prospección de los puntos comunes en la democracia en los conceptos de Ross y Kelsen, dando un concepto de mínimos en el cual "se trata de la democracia como un simple método".

No podemos dejar de valorar los notables logros que representarían los límites que pusieron los atenienses dentro del propio concepto de democracia, pues incluso su política descansaba sobre este concepto fundamental que permitía, entre otras cosas, la participación directa de los ciudadanos en las dos funciones del Estado, así como la capacidad en la asamblea de ejercer su poder soberano, incluso el avance ya de la alternabilidad entendiendo como la prohibición que una misma persona no pueda ocupar dos veces el mismo puesto, salvo miembros del ejército y el establecimiento de unos plazos dentro de los cuales se podía ejercer el cargo público (Held, 2008:55).

Una de las definiciones más claras sobre esta materia es aquella que nos ofrece el italiano Norberto Bobbio (1985), quien se basó en tres principios institucionales:

a. Reglas fundamentales que guían, qué está autorizado y cómo decidir sobre ello;

b. Por el grado de participación de los miembros de la sociedad. (Será más democrático cuanto mayor número de personas participan directa o indirectamente al momento de decidir).

c. Elecciones o participación real.

Coincidimos con Touraine (1994), quien señalaba que “(...) lo que define a la democracia no es sólo un conjunto de garantías institucionales o el reino de la mayoría, sino ante todo la afirmación de una libertad personal con derecho a identificarse con una colectividad social, nacional o religiosa particular".

No obstante, la retórica que se presenta en el plano político, se reduce a mostrarla tan solo como un sinónimo de la decisión de la mayoría. Esto genera precisamente serios riesgos que serán tratados en el presente estudio y que se fundamentan en la idea de Ernesto Garzón Valdés, sobre los que él denomina "cotos vedados" que no son otra cosa que aquellos derechos que no pueden verse sobrepasados por una decisión democrática. 
“(...) El principio de la soberanía popular y la regla de la mayoría - se subordina a los principios sustanciales expresados por los derechos fundamentales y relativo a lo que no es lícito decidir y a lo que no es lícito no decidir" (Ferrajoli, 1999:52).

Por lo que de esta manera vemos un extraño acercamiento entre el Derecho a la moral, lo cual se traduce como la tensión existente y que le es propia a aquella que tiene el Derecho Constitucional y la democracia. (Rey, 2012: 39), pues existen derechos que no pueden ser puestos por parte de la sociedad a una especie de regateo político, entre quien los extiende o los limita a través de un referéndum o consulta popular.

Todo lo antes señalado, en el ámbito latinoamericano lo encontramos de manera efectiva, a través de uno de los Pactos Internacionales más representativos, la Convención Americana de Derechos Humanos, CADH, así como en el Sistema Interamericano de Derechos Humanos, SIDH, el cual permite su aplicación e incorporación en cada uno de los países de la región, y que tienen por objetivo comprometerse a respetar los derechos y libertades y garantizar su libre y pleno ejercicio a todas las personas sin ningún tipo de discriminación (Art. $1 \mathrm{CADH})$.

No obstante, enmarcaremos el estudio en una rápida aproximación a los tipos de democracia sobre todo en el contexto actual en el cual muchos exigen el regreso a las esencias, en este caso al modelo de democracia directa por un supuesto fracaso del modelo representativo.

\section{EL ESTADO PURO DE LA DEMOCRACIA. LA DEMOCRACIA DIRECTA}

A criterio de Bobbio (1985:54), sugerir que éste tipo de democracia se entiende como la participación directa en todas las decisiones, por parte de todos los miembros de la sociedad, y es una aspiración por decirlo menos insensata. Lo cual no lo comparte Sartori (2009) quien entiende a la democracia directa como "(...) tal se basa en las interacciones "cara a cara" entre presentes, entre personas que se incluyen mutuamente y que cambian de opinión escuchándose entre sí".

Si los atenienses del siglo $\mathrm{V}$ a. C. disponían de todas las herramientas que en la actualidad nos ofrecen las Tecnologías de la Información y Comunicación, TIC, a lo mejor supondrían que el manejo y la aplicación de lo que representa el estado puro de la democracia directa, sería un modelo exitoso sin discusión, pues los ciudadanos no deberían acudir todos los días a una Asamblea pública para tomar sus decisiones, primero por razones logísticas puesto que no todos ingresarían en el Coliseo, ni tampoco por la forma de tomar las decisiones. Lo cual y a criterio de Sartori (2009), puede llegar a la forma de democracia electrónica en la cual todos los ciudadanos nos encontraríamos en la situación de que todos los días en nuestro ordenador, debamos contestar algunas preguntas tan solo con un sí o un no, lo cual sería ya un autogobierno integral.

En este contexto James Fishkin (1995), plantea a su vez el modelo Qube (Warner-Amex Qube, un sistema de televisión por cable que permite a las personas votar desde sus casas a través del mando a distancia), en el cual se encuentran tres categorías de teledemocracia directa: la primera que corresponde al modelo sencillo, en la cual a los ciudadanos se les presentaría dos propuestas sobre políticas públicas y serían estos quienes votarían de manera directa. Sin embargo, la crítica se centra en dos cuestiones, la primera que es un riesgo demasiado grande otorgar ese poder a personas que no se encuentran preparadas, y el segundo que la demagogia primaría e incluso so pretexto de la mayoría se podrían vulnerar 
derechos de terceros. La segunda categoría sería el Qube representativo en el cual serían unos representantes quienes decidirían en base a varios sondeos de opinión cuáles son los temas polémicos a los cuales se deberían dar una respuesta. El problema radica en la falta de deliberación así como de nuevo en la tiranía de las mayorías, y en la esencia del modelo plebiscitario, donde sólo existiría un sondeo de opinión y sobre este los representantes deciden. Esta categoría si bien es cierto no se encuentra configurada en nuestras democracias, su aplicación se da día a día ante la necesidad por parte de los políticos de dar respuestas a los temas que preocupan a la ciudadanía.

No podemos olvidar que, la hipótesis sobre el gobierno de las mayorías, nace de John Stuart Mill, quien señaló que es la única forma para contar con democracias pues a su criterio la considera como “(...) el requisito más fundamental de la democracia y que la combinación de elecciones por mayoría relativa o absoluta y gobierno parlamentario puede dar lugar a un gobierno minoritario" (Lijphart, 2006:269).

Frente a esta posición antes mencionada, está la oposición que la califica como "la tiranía" de la mayoría, pues se sostiene que puede presentarse la situación en la cual este principio mayoritario tenga un carácter imperfecto, “(...) por ello debe estar cercada por un conjunto de límites que preserven al sujeto colectivo de sus más patológicas tendencias" (Chueca, 1993:180). Pues si se apoya totalmente la posición de Mill, se podría llegar incluso a la destrucción del Estado democrático, al plantear por ejemplo atropellos a los derechos constitucionalizados.

\section{LA DEMOCRACIA REPRESENTATIVA}

Partir de la premisa mediante la cual el Estado parlamentario, constituye un sinónimo de democracia representativa, provoca equívocos que deben ser evitados a fin de no distraer el Estado de la cuestión, tal como lo señala Bobbio (1985:56) "La expresión democracia representativa, significa, genéricamente, que las deliberaciones colectivas, ósea, las deliberaciones que afectan a toda la comunidad son tomadas no directamente por aquellos que forman parte de la misma, sino por personas elegidas para tal propósito. Y punto".

De esta manera, en el ámbito latinoamericano, son pocos los Estados que se encuentran configurados a través de un modelo parlamentario al cien por ciento, y pese a ello la democracia representativa actúa en otras esferas del mismo (Véase, la representatividad que tienen los asambleístas en la República Bolivariana de Venezuela; los diputados en Nicaragua; y los asambleístas provinciales y nacionales en Ecuador, respectivamente).

No olvidemos que doctrinalmente se ha venido discutiendo si el representante, llámese diputado o asambleísta, se trata de un mandante en el sentido estricto que lo único que hace es cumplir las órdenes que el pueblo soberano le entregó, o al contrario se convierte en un fiduciario, lo cual sin duda le otorgaría mayor libertad para desenvolverse. Sin embargo, más allá del "quién", Bobbio (1985) establece que además se debe analizar "qué representa", son los intereses particulares o generales del ciudadano, es aquí donde la brecha y el concepto aparentemente adecuado de democracia representativa como modelo ideal se rompe y choca con lo que los individuos esperan.

Giovanni Sartori, a su vez realiza una reflexión entre democracia directa y representativa, que nos permite medir las ventajas o problemas que se puedan presentar entre una y otra, así “(...) en la democracia representativa es probable que todos salgan ganando algo (la suma es positiva) porque las decisiones de los representantes se negocian de forma que cada uno 
reciba un trozo del pastel. En cambio, en las democracias directas no hay negociación, no hay intercambio, y, por tanto, quien se impone se lleva todo el plato" (Sartori, 2009: 41).

En la última década, Latinoamérica ha vivido una crisis institucional, afectada sobre todo por la deslegitimación que sufrieron los partidos políticos que eran los depositarios de la confianza y la representación de los ciudadanos en las distintas esferas del Estado. Todo aquello generó una situación en la cual los ciudadanos buscaban participar en el proceso de la toma de decisiones a través de otras posibles vías.

\section{LOS MECANISMOS DE PARTICIPACIÓN Y LA DEMOCRACIA PARTICIPATIVA}

La tiranía de las mayorías, se presenta cuando el problema de la democracia no es planteado por los pocos sino por los muchos, situación que fue temida incluso por los constituyentes estadounidenses que pensaban que podía presentarse un ejercicio absoluto del derecho de la mayoría.

Las jóvenes democracias de finales del siglo pasado, se caracterizaron por una dinámica política en la cual el modelo representativo se vio influenciado de manera directa, por factores determinantes de clientelismo, lo cual generó a su vez un desencanto entre gobernantes y gobernados que vieron la necesidad de encontrar en otros modelos la forma de alcanzar una verdadera representatividad.

La excesiva burocratización de las instituciones, así como la apertura de puertas a situaciones propias del clientelismo, derivaron en un verdadero malestar de la población que no se sentía representada en sus gobernantes, quienes ya no gozaban de legitimidad y peor aún de credibilidad. Todo esto se reflejaba ya en dos factores fundamentales: a) inequidad social; y, b) asimetría en el acceso a servicios públicos de manera universal a la población.

Para ello fue necesario aplicar un nuevo modelo de democracia, la denominada participativa y deliberativa, la cual interfiere sistemáticamente el plano social y el estatal, y los funde; dejando un espacio público importante, abierto a la participación de los individuos, los cuales pretenden no sólo a la suma de propuestas, sino también a la toma de decisiones, perspectiva que es en un primer momento abordada de manera directa por organizaciones de la sociedad civil y que con el tiempo son realizadas de manera directa por los ciudadanos, quienes ya no necesitan de intermediarios sino su deseo es hacerlo directo y sin dilaciones.

Si se pretende que el modelo funcione en su totalidad, aún resta un proceso a largo plazo en el cual los mecanismos que permitan incidir en la toma de decisiones y que recién constan en los instrumentos jurídicos, sean conocidos por los ciudadanos, por lo que es necesario un proceso de educación y aprendizaje de educación cívica y constitucional, así como trabajar en la construcción de una política de responsabilidad social y rendición de cuentas (accountability), la cual debe estar debidamente articulada con la cultura política, concepto que David Mathews llama "la política para la gente", postulados que han sido adoptados por "los regímenes revolucionarios" de Venezuela, Nicaragua y Ecuador; en los cuales en teoría, los ciudadanos son los principales actores del cambio. (Murillo y Pizano, 1999:125 -129)

\section{POSTULADOS Y GARANTÍAS MÍNIMAS}

Es ya clásico el estudio que en 1974, Robert Dahl realizó sobre la democracia, en el cual estableció tres postulados básicos de los cuales se desprendían aquellas garantías mínimas, 
que deberían poseer todos los ciudadanos dentro de un Estado Democrático, y que expresaba según queda reflejado en la Tabla 1.

Tabla 1

\begin{tabular}{|c|c|c|c|}
\hline Postulados & $\begin{array}{l}\text { Garantías } \\
\text { Institucionales } \\
\text { mínimas }\end{array}$ & $\begin{array}{c}\text { Convención Americana de } \\
\text { Derechos Humanos }\end{array}$ & Constituciones \\
\hline $\begin{array}{l}\text { Formular propias } \\
\text { preferencias }\end{array}$ & $\begin{array}{l}\text { Libertad de } \\
\text { asociación }\end{array}$ & $\begin{array}{l}\text { Art. 16. Libertad de } \\
\text { Asociación }\end{array}$ & $\begin{array}{l}\text { Venezuela: Art. 67; } 118 \\
\text { (Sindical) } \\
\text { Nicaragua: Art. 49; } 109 \text { (Aso. } \\
\text { Agr. Campesina) } \\
\text { Ecuador: Art. 326 \# } 7 \text { (Sindical) }\end{array}$ \\
\hline $\begin{array}{l}\text { Expresar preferencias } \\
\text { a la sociedad y al } \\
\text { gobierno (acciones } \\
\text { individuales y } \\
\text { colectivas) }\end{array}$ & $\begin{array}{l}\text { Libertad de } \\
\text { Expresión }\end{array}$ & $\begin{array}{l}\text { Art. 13. Libertad de } \\
\text { Pensamiento y de } \\
\text { Expresión }\end{array}$ & $\begin{array}{l}\text { Venezuela: Art. } 57 \\
\text { Nicaragua: Art. } 30 \text {; Art. } 90 \\
\text { Ecuador: Art. } 66 \# 6 .\end{array}$ \\
\hline \multirow{6}{*}{$\begin{array}{l}\text { Consideración de } \\
\text { expresiones con } \\
\text { igualdad de trato }\end{array}$} & $\begin{array}{l}\text { Libertad de } \\
\text { voto }\end{array}$ & Art. 23. Derechos Políticos & $\begin{array}{l}\text { Venezuela: Art. } 63 \\
\text { Nicaragua: Art. } 51 \\
\text { Ecuador: Art. } 62\end{array}$ \\
\hline & $\begin{array}{l}\text { Derecho } \\
\text { grupos } \\
\text { electorales }\end{array}$ & $\begin{array}{l}\text { Art. 23. Derechos Políticos } \\
\text { Art. 16. Libertad de } \\
\text { Asociación } \\
\text { Art. 15. Derecho de } \\
\text { Reunión } \\
\end{array}$ & $\begin{array}{l}\text { Venezuela: Art. } 62 ; 67 \\
\text { Nicaragua: Art. 50; 51; } 55 \\
\text { Ecuador: Art. } 61 \# 8 ; 108\end{array}$ \\
\hline & $\begin{array}{l}\text { Fuentes } \\
\text { alternativas de } \\
\text { información }\end{array}$ & $\begin{array}{l}\text { Art. 13. Libertad de } \\
\text { Pensamiento y de } \\
\text { Expresión } \\
\text { Art. 14. Derecho de } \\
\text { Rectificación o Respuesta }\end{array}$ & $\begin{array}{l}\text { Venezuela: Art. 28; } 58 . \\
\text { Nicaragua: Art. } 26 \text { \# 4; Art. } 66 . \\
\text { Ecuador: Art. 16; 18, } 66 \text { \# } 7 .\end{array}$ \\
\hline & $\begin{array}{l}\text { Elegibilidad } \\
\text { cargos públicos }\end{array}$ & Art. 23. Derechos Políticos & $\begin{array}{l}\text { Venezuela: Art. } 70 \\
\text { Nicaragua: Art. } 51 \\
\text { Ecuador: Art. } 61\end{array}$ \\
\hline & $\begin{array}{l}\text { Elecciones } \\
\text { libres y } \\
\text { objetivas }\end{array}$ & Art. 23. Derechos Políticos & $\begin{array}{l}\text { Venezuela: Art. } 63 ; 70 \\
\text { Nicaragua: Art. } 51 \\
\text { Ecuador: Art. } 61 \# 7 .\end{array}$ \\
\hline & $\begin{array}{l}\text { Instituciones y } \\
\text { políticas } \\
\text { dependientes } \\
\text { del voto. }\end{array}$ & Art. 23. Derechos Políticos & $\begin{array}{l}\text { Venezuela: Capítulo cuarto } \\
\text { Nicaragua: Art. 51. Ecuador: } \\
\text { Capítulo quinto Derechos de } \\
\text { participación }\end{array}$ \\
\hline
\end{tabular}

Fuente: Elaboración propia

\section{LOS RIESGOS EN AMÉRICA LATINA DE LA DEMOCRACIA DELEGATIVA}

Guillermo O'Donnell (1994), se refiere a lo que él denomina una nueva "especie" de democracia, lo cual tiene que ver más con la parte empírica, que la teórica. No todas las transiciones democráticas derivan en un modelo similar. Pero para este autor argentino, no necesariamente ese pasado autocrático y autoritario se refleja posteriormente en una democracia, sino que centra sus características en consecuencias socioeconómicas que van a influir directamente en las jóvenes democracias.

Sin embargo, el autor citado toma el ejemplo de Argentina, Perú, Brasil, incluido Ecuador y señala que si bien es cierto cumplen los criterios que fueron planteados por Robert Dahl, no 
pueden ser democracias representativas, sino más bien delegativas: “(...) son democracias consolidadas -es decir, institucionalizadas-, pero pueden ser duraderas. En muchos casos no se observan señales de una amenaza inminente de regresión autoritaria, ni de progresos hacia una democracia representativa" (O'Donnell, 1994:8). El problema que salta a la vista es que no necesariamente estas democracias influyen a que sus ciudadanos deseen regresar a regímenes autoritarios, sino que son incapaces de desarrollar e implementar instituciones democráticas, lo cual no sucede siempre en los países latinoamericanos, que piensan que por contar con un gobierno elegido democráticamente, y esto ya es sinónimo de institucionalidad, lo cual resulta incorrecto.

Y justo el caso de éxito, a diferencia de lo que sucede en los países objeto de estudio; en el caso de Chile si se dio: “...una coalición decisiva de líderes políticos con un amplio respaldo, que prestan mucha atención a la creación y el fortalecimiento de las instituciones políticas democráticas" (O’Donnell, 1994). Todo lo cual repercute en el adecuado manejo y solución de problemas económicos y sociales.

Ahora bien, la democracia delegativa se basa en un supuesto básico que sin duda se refleja en los actuales sistemas de gobiernos de muchas naciones latinoamericanas "(...) quien sea que gane una elección presidencial tendrá el derecho a gobernar como él (o ella) consideren apropiado", frente a lo cual nos opondríamos y decimos que justamente el límite que se debe establecer en estos casos deben ser los derechos fundamentales de los seres humanos, que en el continente están representados a través de la CADH y todo el SIDH. Caso contrario de estas democracias delegativas, pueden llegar al extremo de que so pretexto de la votación que los llevó al poder, el Presidente crea que encarna la soberanía popular y se considere el ungido con su voluntad para gobernar como le plazca; incluso llegando en momentos a deslegitimar a los controles lógicos como el político del legislativo y judicial.

Sería entonces de esta manera que el presidente apoyado en la teoría del dominio de las mayorías se convierte en la "encarnación de la patria". A diferencia de la democracia representativa, la democracia delegativa evade el principio de rendición de cuentas, apartando de sus gestiones esta visión republicana de la democracia, pues la considera como un estorbo en el cumplimiento de sus objetivos, pues caso contrario su gestión se tornaría lenta y los niveles de satisfacción disminuirían en los ciudadanos.

Cabe señalar que usualmente los presidentes que encarnan las democracias delegativas se presentan como salvadores de la patria, normalmente en situaciones de crisis sociales o económicas, con más fuerza que ingenio creen que pueden mejorar las situaciones. La legitimidad carismática pretende ser pues prioritaria frente a la legitimidad democrática, con este modelo de caudillaje peculiar.

\section{LOS CASOS DE VENEZUELA, NICARAGUA Y ECUADOR ANTE LA NECESIDAD DE GENERAR GOBIERNOS DEMOCRÁTICOS}

\subsection{Venezuela. Democracia directa y Estado comunal}

La Fuga del presidente Pérez Jiménez de Caracas, el veintitrés de enero de 1958, marcó el fin del gobierno militar característico de Venezuela desde la independencia. En el choque de una sociedad civil débil y fragmentada, los petrodólares se convirtieron en el principal baluarte. Los ingresos petroleros pagaron la factura de la democracia pactada, "Pacto de Punto Fijo". Esta política abrió las puertas a los partidos Acción Democrática (AD) y el Comité de Organización Política Electoral Independiente (COPEI), a instaurar un modelo bipartidista que estuvo vigente hasta 1993 (Leynn Karl:1986). Posteriormente, Rafael 
Caldera, fundador del COPEI, ganó la presidencia de la República, a través de un partido creado al efecto en esa elección (convergencia). El seis de diciembre de 1998, se celebraron elecciones generales resultando electo presidente de la República Hugo Chávez Frías. Con la muerte de Chávez (marzo de 2013) es electo en elecciones generales, Nicolás Maduro (abril de 2013) para ejercer el cargo de presidente de la República en el periodo constitucional (2013-2019).

La Constitución de Venezuela de 1999, fue promulgada bajo una enorme tensión política, que puso en tela de juicio la legitimidad del constituyente. La Corte Suprema (sala político administrativa) fue el escenario de sendos recursos de interpretación. Las demandas se centraron sobre la viabilidad jurídica de convocar un referendo consultivo para establecer, conforme al art. 181 de la Ley Orgánica del sufragio, una asamblea constituyente. Se presentó entonces la disyuntiva, entre soberanía popular y la supremacía constitucional.

La batalla legal no fue obstáculo para la celebración del referendo, que se llevó a efecto el veinticinco de abril de 1999. Participaron 4.137.509 de los 11.022.936 electores registrados. La abstención electoral fue del $62 \%$. La votación por el (SI) representó el 92,4\% contra el (NO) que solamente llegó a obtener un 7,6\%. (Véase los datos estadísticos del Boletín Electoral Latinoamericano No. XXII, de julio a diciembre de 1999).

Con la vigencia de la Constitución de 1999, se estableció, según prescribe el art. 2, un Estado Democrático y Social de Derecho y de Justicia. El art. 136 estableció que el poder público se descentraliza en distintos poderes (Municipal, Estatal y Nacional). El poder público se conformó en (Legislativo, Ejecutivo, Judicial, Ciudadano y Electoral). El constituyente estableció una multiplicidad de órganos asignándoles a cada cual, según corresponda, funciones propias. No obstante, es menester formularse la pregunta, de que si estas atribuciones que tienen asignadas los órganos estatales, le conceden primacía a uno sobre los otros en detrimento del Estado de Derecho y los derechos fundamentales de los individuos.

La Constitución en el art. 4 también regulaba que Venezuela es un Estado descentralizado. Se parte de la premisa de que para que exista efectiva participación política se debía concebir al individuo como el único titular del poder. En base a esta praxis, se llegaron a concebir constitucionalmente todos los tipos inimaginables de referendos (art. 6, 70, 72, 197, 198 y 203). La participación a nuestro entender, no puede ni debe quedar reducida a la democracia directa como se ha entendido hasta ahora, ni mucho menos puede esta conllevar a la eliminación de la representación. En comunidades políticas los mecanismos de autogobiernos deben gozar de autonomía propia. Por lo que, evidentemente no existe, ni existirá una auténtica participación, si lo que se intenta es implementar que los individuos participen en asambleas de ciudadanos controladas de forma directa a través de las directrices claras y concretas del poder central.

Todo parece apuntar que en Venezuela, en contra del mandato representativo, se han creado instancias políticas mediante ley, que no tienen otro objetivo que el vaciamiento de competencias a los órganos estatales. A estas instancias se le ha encomendado funciones políticas sin que se garantice todavía su carácter electivo mediante sufragio universal, libre, directo y secreto, y sobre todo sin que se asegure su autonomía política y su carácter pluripartidista.

Ahora bien, en diciembre de 2007 se procedió a una consulta popular, con el objetivo de implantar en Venezuela un "Estado del poder popular" o bien "Estado comunal". La consulta fue rechazada por el pueblo. No obstante, en burla al único titular del poder "poder ciudadano" la Asamblea Nacional elevó en el año 2009 a rango de Ley Orgánica los 
Consejos Comunales, que viene a definir por un lado, el modelo de un nuevo Estado, paralelo al Estado constitucional y por otro, una nueva geometría del poder que puso en aquel entonces en tela de duda la credibilidad del poder judicial.

Finalmente, el texto constitucional venezolano regula un gran número de garantías jurisdiccionales, derechos sociales, distintos mecanismos de participación ciudadana, y un amplio catálogo de derechos fundamentales. Su aplicación efectiva dependerá en gran medida del riesgo, por parte de los operadores políticos, de que sus acciones se encuadren dentro del concepto de democracias delegativas.

\subsection{Nicaragua. Entre democracia representativa y democracia directa}

En Nicaragua, la Dictadura somocista (1936-1979) se caracterizó por gestar un gobierno clientelar, y una política de "pactos" oportunistas entre las llamadas paralelas históricas, (liberales y conservadores), que daban oxígeno al somocismo más allá de la voluntad del electorado.

La Dictadura, en todo el proceso de gestación de la revolución utilizó todos los medios a su alcance para reprimir y violar de manera desmesurada, sin ningún reparo, los derechos humanos de los nicaragüenses. La intervención Norteamericana en Nicaragua (1910-1933) dejó como herencia, entre otras cosas, un cuerpo armado denominado "Guardia Nacional". Este cuerpo militar fue el principal aparato represivo del régimen y el principal escudo de la Dictadura. Como se sabe, por órdenes expresa de Somoza, la Guardia asesinó el veintiuno de febrero de 1934 al General Sandino y más tarde, el siete de noviembre de 1976, al principal ideólogo y líder de la revolución sandinista, Carlos Fonseca Amador.

En Julio de 1979, la revolución puso fin a la Dictadura. Una Junta de Gobierno controlada por los sandinistas asumió el control del nuevo Estado. A partir de entonces se derogó, desde un Estatuto Fundamental, la Constitución Política de 1974. Los sandinistas pusieron en marcha su plan de gobierno, aprobado en 1969, cuyas notas características fueron, el pluralismo político, la economía mixta, y en el plano exterior el no alineamiento internacional.

Los poderes del Estado revolucionario, se estructuraron a su vez de este modo: un Ejecutivo desempeñado por la Junta de Gobierno, el Legislativo en manos de un Consejo de Estado, y por último el Judicial residenciado en una Corte de Justicia compuesta de magistrados designados por la Junta de Gobierno.

La conformación de la Junta de Gobierno, fue el resultado de la estrategia sandinista de alianzas pluriclasistas, como símbolo de la unidad nacional. El Consejo de Estado fue un órgano semicorporativo. Sus miembros eran designados por los organismos de masas o estructura de legitimidad del nuevo régimen a través de consultas o asambleas. No obstante, la abstracta soberanía radicó esencialmente en la Junta de Gobierno, desapareciendo los demás centros del poder normativo.

En noviembre de 1984, el pueblo nicaragüense acudió a las urnas para hacerle frente a la agresión norteamericana y legitimar a la vez el proceso revolucionario. En aquel entonces se eligieron por un período de seis años, al Presidente y Vicepresidente de la República, y además a noventa y seis representantes que formarían la Asamblea Nacional y que tendría, durante sus dos primeras legislaturas, funciones constituyentes.

La guerra de guerrillas de los sandinistas con el grupo armado conocidos popularmente como "contrarrevolucionarios", financiados por la administración Reagan, dio lugar a que el proceso constituyente se revistiera de unas características especiales. El Estado de emergencia fue el común denominador. Con todo, el nueve de enero de 1987, entró en 
vigencia, la Constitución. Se consagró un régimen presidencialista reforzado, que debilitó las orbitas respectivas de los demás poderes del Estado.

La Constitución significó siguiendo a Vintro Castells (1987) que "el país entronque en la tradición liberal democrática". Ya desde los primeros años de la revolución la Junta de Gobierno, había aprobado y ratificado la CADH, celebrada en San José, Costa Rica en 1969 (Gaceta No. 67 de 26 de noviembre de 1979) y la Convención Americana sobre Derechos Humanos (Gaceta No. 53, 54 y 55 del 03, 04, 05 de marzo de 1980). El Estatuto sobre Derechos y Garantías de los Nicaragüenses (Gaceta No. 11 de 17 de septiembre de 1979), que fue una especie de Constitución (1979-1986), intentó salvaguardar los derechos individuales, civiles, económicos, sociales, culturales y políticos. En su art. 50 legitimaba, a cualquier persona a interponer el recurso de amparo, por violación de los derechos reconocidos en el Estatuto Fundamental de la República o en el de Derechos y Garantías de los Nicaragüenses.

Ahora bien, con la entrada en vigor de la Constitución, se subrayó por un lado, la necesidad de estructurar, en base a la realidad política nicaragüense, un gobierno democrático; y por otro, el reconocimiento constitucional de los derechos fundamentales. Se estableció pues, en el art. 188, la posibilidad de entablar el recurso de Amparo en contra de "toda disposición, acto o resolución y en general en contra de toda acción u omisión de cualquier funcionario, autoridad o agente de los mismos que viole o trate de violar los derechos y garantías consagrados en la Constitución Política".

En 1990 triunfó una coalición de partidos políticos (Unión Nacional Opositora) encabezada por Violeta Barrios de Chamorro, viuda del periodista conservador, Pedro Joaquín Chamorro, que fue en aquel entonces, ante de su muerte violenta en enero de 1978, codueño del diario más antiguo de centroamericana, La Prensa y miembro también de una familia de hondas raíces oligarcas. Doña Violeta intentó desmantelar el Estado sandinista. Producto de ello se generaron fuertes tensiones entre el Ejecutivo y el Legislativo. En contra de la voluntad del Ejecutivo se inició en 1995 una reforma constitucional. En suma, disminuyó los poderes exorbitantes del presidente de la República. La reforma estableció un mayor control político por parte del parlamento, y a la vez una mayor independencia del Poder Judicial.

Los sandinistas regresan al poder en el año 2006, Daniel Ortega logró en el año 2010, un quebrantamiento de la Constitución y consiguió, en contra de la misma, en noviembre de 2011, hacerse nuevamente con el poder. Para ello, utilizó una nueva figura atípica de uso común de los países de América Central. La Corte Suprema de Justicia, como poder constituido y principal garante del orden constitucional, declaró pues, inaplicable los artículos 147 inciso a), y 178 de la Constitución para permitir la reelección presidencial. Los artículos hacen referencia a lo que comúnmente se ha denominado como el "doble candado", en el que no puede ser candidato a presidente "el que ejerciere o hubiese ejercido en propiedad la presidencia de la República en cualquier tiempo del período en que se efectúa la elección para el siguiente período, ni el que la hubiera ejercido por dos periodos presidenciales". Ortega precisamente no podía ser presidente primero, porque en aquel entonces ejercía el cargo, y segundo, porque ya fue electo en 1985.

Nicaragua, actualmente se encuentra sumergida en una crisis institucional, provocada en parte por la falta de acuerdo, entre los partidos políticos representados en el seno del órgano legislativo. Diez Magistrados del Poder Electoral, cinco funcionarios del Consejo Superior de la Contraloría General de la República, el Procurador y Subprocurador para la Defensa de los Derechos Humanos, el Fiscal General de la República, doce Magistrados de la Corte 
Suprema de Justicia, entre otros, forman la gama de más de treinta y cinco representantes de los distintos poderes del Estado que se encuentran amparados en el Decreto Ejecutivo 32010, hasta tanto la Asamblea Nacional no nombre nuevos representantes. En el mes de mayo de 2014, venció el período a los restantes cuatro Magistrados de la Corte de Justicia, con lo cual, la Corte en Pleno, estará con representantes con mandatos caducados desempeñando la más alta magistratura del Poder Judicial

La Constitución sólo atribuye la potestad legislativa al ejecutivo en el art. 150.3, para “dictar Decretos Ejecutivos en materia administrativas", pero en ningún caso para dictar decretos con valor de ley para prorrogar el período a representantes de los distintos poderes del Estado. Esta incertidumbre jurídica, bastante compleja en el sistema político nicaragüenses, no está prevista ni en la Constitución ni en las distintas leyes orgánicas del Estado Nicaragüense. No obstante, deja en evidencia que, en contra de la voluntad del electorado, se producen situaciones atípicas por considerar que aquel, no comprende las disyuntivas del modelo político nicaragüense.

El régimen de Ortega pretende adaptar con ciertos matices el modelo de democracia, implementado en Venezuela. En un primer momento nacieron los C.P.C (Consejo del Poder Ciudadano) que no llegaron a ser un quinto poder del Estado, porque para eso debe reformarse la Constitución sino que con la aprobación del Código de la Familia, el veintiuno de febrero de 2013, se crearon los "Gabinetes de Familia, Salud y Vida" concebidos entre otras cosas, como un sistema de organización estatal "integrados por todos los ciudadanos que desean reflexionar, aprender, aportar y actuar juntos sobre todos los temas de la vida". En realidad, el espíritu de los "Gabinetes de Familia" no tiene otra cosa que, establecer un control partidario y politizado no solo de las familias nicaragüenses, sino desarrollar a la vez una extensa red de control que influya en beneficio del partido de gobierno. Esos Consejos, que la oposición considera reedición de los Comités de Defensa Sandinistas (1979-1990) son coordinados con una orientación vertical por la primera dama, Rosario Murillo.

Ahora bien, en las elecciones generales de 2011, el F.S.L.N obtuvo 91 escaños en la Asamblea Nacional sobre un total de 93. La mayoría absoluta en el órgano legislativo le permitió aprobar, en primera y segunda legislatura como lo demandan los art. 191 y 192 de la Constitución, una reforma constitucional únicamente con los votos favorables del partido de gobierno. Se publicó, entonces el diez de febrero de 2014, la Ley 854, de Reforma Parcial a la Constitución Política Nicaragüense. En suma, la reforma establece por un lado, la reelección indefinida y a la vez desaparece la posible doble vuelta electoral e incorpora que el Presidente es elegido en una sola vuelta por mayoría relativa de votos, y por otro, incorpora los valores cristianos, los ideales socialistas y, las prácticas solidarias (art. 4 y 5) y se eleva a rango constitucional los mecanismo de la democracia directa, entre otros, los presupuestos participativos, los consejos territoriales y los consejos sectoriales (art. 2, 6 y 7).

\subsection{Ecuador. De la lucha contra la partidocracia a la Revolución Ciudadana}

Al igual que muchas otras democracias a nivel latinoamericano, la ecuatoriana puede ser calificada como joven, ya que es desde finales de la década de los setenta, cuando el país retoma el cauce democrático dejando atrás cerca de dos décadas de dictaduras militares: “(...) desde 1979 ha cumplido sin mayores problemas con la lista de chequeo de la poliarquía. Esto quiere decir que al ser colocado en el continuum autoritarismo-democracia se encontraría en algún lugar un tanto alejado de la forma pura de democracia, pero siempre a mayor distancia de la forma pura del autoritarismo". (Pachano, 2008:7), y se reincorpora con un nuevo texto constitucional y con las correspondientes elecciones generales de las cuales resulta vencedor Jaime Roldós Aguilera, quien llegaría en una coalición de los partidos, por 
un lado uno de corte populista como "Concentración de Fuerzas Populares", CFP y el partido demócrata-cristiano, que sigue la línea alemana denominado "Democracia Popular", DP. Una de las particularidades de su mandato, fue el no llegar a completarlo, pues murió en un accidente aéreo en el mes de mayo de 1981, lo que ocasionaría que el vicepresidente y cercano a los demócratas cristianos asumió la presidencia por el resto del período, el cual entre sus principales acciones benefició a los empresarios privados con la denominada "sucretización de la deuda".

Con los antecedentes antes señalados, el país quedaría marcado con una tendencia cercana al centro derecha, que en el siguiente período se radicalizaría hacia la derecha con la victoria presidencial en el año 1984 de León Febres Cordero, líder del Partido Social Cristiano, PSC, durante el cual se caracterizó por la confrontación con los nacientes movimientos sociales cercanos a la izquierda a los cuales combatió, llegando a eliminar por la fuerza a células insurgentes como las de Alfaro Vive Carajo, AVC. Su período se complementó, con la ayuda continua a empresarios privados de la costa ecuatoriana, y una polémica militarización de la Corte Suprema de Justicia.

Durante el período 1988-1992 gobernó el Ecuador Rodrigo Borja Cevallos, representante de uno de los partidos que mayor repercusión ha tenido en las últimas décadas y es la Izquierda Democrática, ID (cercano al Partido Socialista Obrero Español, PSOE). Durante su período tuvo que contrarrestar al movimiento indígena, que hizo su aparición a través de un gran levantamiento denominado "500 años de resistencia indígena".

Cual si se tratase de un vaivén político, el siguiente mandatario de 1992-1996, fue Sixto Durán Ballén, que regresó a un perfil cercano a la derecha y al centro derecha, como ex dirigente del PSC, pero esta vez lo hizo a través de un partido político creado solamente para la contienda electoral, el Partido de Unidad Republicana, PUR, en coalición con el Partido Conservador. Su período se caracterizó por afrontar la guerra con el Perú, conocida como "Guerra del Cenepa" en la cual Durán Ballén ejerció su liderazgo para mantener unido al país, y por otro un proceso agresivo de privatización de los servicios públicos, a través de reformas legislativas y de una flexibilización laboral (Donoso, 2009).

El período que continúa, corresponde a una rápida aparición del polémico Abdalá Bucaram Ortiz, quien estuvo tan sólo seis meses en el poder y que causó uno de los primeros procesos de inestabilidad política del Ecuador pues tuvo que abandonar el país debido a la reacción popular en las calles que pidieron su salida debido a su peculiar estilo de administrar el Estado, así como a las denuncias de corrupción contra él y su familia. Posterior a ello, se dio un conflicto respecto a la sucesión presidencial entre la Vicepresidenta, Rosalía Arteaga, y el presidente del Congreso Nacional, Fabián Alarcón Rivera, que quedó zanjada con la posesión del segundo como Presidente Interino, quien ratificó su mandato 1997-1998, a través de una consulta popular.

Pese a lo anteriormente señalado, la ciudadanía vio claramente que el modelo que se instauraba venía impulsado en un proyecto neoliberal que buscaba satisfacer al capital versus el ser humano, el cual generó mayores desigualdades en la población, así como una preferencia a favor del sector financiero que sería un actor importante, por el daño que causó a inicios del presente siglo con la crisis bancaria, durante el gobierno del presidente Jamil Mahuad Witt, 1998-2000, representante del centro-derecha y del Partido Democracia Popular, DP (Ortiz, 2008:14). Luego de la caída de Jamil Mahuad Witt, debido a las revueltas callejeras lideradas por el movimiento indígena y el ejército ecuatoriano a cargo del Coronel, Lucio Gutiérrez, a quién lo reemplazaría por sucesión presidencial, Gustavo Noboa 
Bejarano, 2000-2003, quien tuvo que afrontar el reto de la dolarización en el país, y serios problemas de ingobernabilidad generados a raíz de la caída de Mahuad.

Uno de los últimos episodios que determinó la importancia de la sociedad civil debidamente organizada frente a la crisis de los partidos políticos, fue el derrocamiento del Coronel Lucio Gutiérrez Borbúa, quien gobernó de enero de 2003 al veinte de abril de 2005, derrocado por la "Rebelión de los Forajidos", ciudadanos de a pie quienes cansados de los atropellos de un régimen autoritario y con serios casos de corrupción, decidieron salir a las calles para pedir la salida del gobierno de Gutiérrez Borbúa.

Los "Forajidos" se mantuvieron organizados, algunos de sus partícipes formaron parte del gobierno transitorio de Alfredo Palacios (2005-2007), incluido el propio Rafael Correa Delgado, quien fue durante algunos meses ministro de Economía. La población cansada de gobiernos que se caracterizaron por dilapidar los fondos públicos y de beneficiar a sectores privados (sector financiero - feriado bancario), en ocasiones de manera espontánea y en otra a través de las organizaciones de la sociedad civil (fundaciones, gremios, colegios profesionales), defendieron la idea de desinstitucionalizar la política, y desconfiar en los partidos políticos, a los cuales los denominarían partidocracia o partitocracia, y que se reflejaba en aquellos partidos clásicos y que habían estado en el poder, de los cuáles sus líderes habían decepcionado a la ciudadanía por sus modelos burocráticos: "El ejercicio irresponsable de las élites, tanto cuando ejercían la oposición como cuando estaban en el gobierno y el manejo de la política como si fuera parte del "negocio personal o familiar". (Freidenberg, 2009:4); pues si bien es cierto los mismos fueron fundamentales para la democracia, las experiencias en el país habían sido tan negativas que era preferible buscar alternativas. Por ello hablar de partidos políticos durante una campaña se debía evitar, llegando al extremo que se convirtió en un sinónimo de desconfianza, status quo y corrupción, algo que llama la atención dentro de un Estado de Derecho.

En este contexto apareció un "outsider" del que sólo se sabía su polémica posición cuando fue Ministro de Economía, Rafael Correa Delgado, y será quien marque un punto de quiebra en la historia del Ecuador, pues los ciudadanos encontraban en la figura de Correa, el representante que cambiaría todo el modelo de Estado, para lo cual se apropió del discurso de devolver a la ciudadanía, lo que era suyo, es decir las instituciones del Estado.

El término peyorativo de "partidocracia" utilizado por Correa, durante su campaña electoral y en su discurso para referirse a aquellas prácticas basadas en el clientelismo y corporativismo, donde los políticos usaron las organizaciones como plataformas para desarrollar sus intereses particulares o familiares, terminaron con la confianza en estas instituciones fundamentales para la democracia, así como de la noción de política en general. Es por ello que la propuesta de la denominada "Revolución Ciudadana", llegó en el momento preciso, y de esta manera se explica el grado de aceptación que generó en la población, lo cual ha sido ratificado con el voto mayoritario en los últimos procesos electorales desde el 2006 hasta la fecha, comportamiento que en lugar de disminuir como sería lógico por el desgaste en el gobierno, sorpresivamente se eleva como la mayoría absoluta alcanzada por PAIS en la Asamblea Nacional (100 legisladores, de 134).

\section{LA IMPOSIBILIDAD DE UN RETROCESO FRENTE A LA NECESIDAD DE MAYOR INSTITUCIONALIDAD}

En la década de los sesenta del siglo pasado, América Latina emprendió un proceso tanto de debate intelectual así como político, respecto a la necesidad de generar procesos 
revolucionarios, a fin de salir del estancamiento económico y social, y para ello se gestaron un sinnúmero de movimientos (células) que recogerían el sentimiento de la población así como también se encargarían de difundir sus propuestas para establecer un nuevo tipo de régimen, el cual fue conseguido en algunos países como Chile donde se instauró un gobierno de perfil socialista. Sin embargo, estos procesos prerrevolucionarios fueron frenados de manera violenta, a través de mecanismos propios de la "lógica de la guerra" en los cuales se buscaba "la aniquilación del adversario y la abolición de las diferencias" (Lechner, 1990:20), lo cual condujo no sólo al derrocamiento del gobierno sino sobre todo a la imposición de un nuevo orden autoritario.

Dos décadas después, se inició un proceso de reflexión sobre la alternativa democrática y sobre todo sobre la renovación del pensamiento político en Latinoamérica, donde de manera directa se criticarían dos aspectos: tanto las dictaduras militares, así como las recetas neoliberales aplicadas; y se ofrecía como alternativa la apertura a la sociedad civil para que participe de manera activa, lo cual se hizo a través de procesos de modernización de las instituciones, teniendo en cuenta que no en todo el continente se hizo de manera similar, sino al contrario, de manera paulatina, pues ya no sólo se trataba de institucionalizar la democracia, sino de intentar construir sobre ella, gobiernos que otorgarían mejores condiciones de vida a sus ciudadanos.

Para Alain Touraine (1994), la crisis de la representación política puede llevar al debilitamiento de las democracias, lo cual le convertiría en un objetivo fácil de derrotar ya sea desde arriba (poder autoritario) o desde abajo (revueltas populares y violencia), reflexión que se la hace al analizar la situación de los distintos Estados en las últimas décadas del siglo pasado en las cuales la presencia de dictaduras y gobiernos autoritarios fue la constante en los distintos continentes.

Ferrán Requejo Coll (1990), al referirse a los estudios que hace D. A. Rustow, padre de las transiciones democráticas, señalaba los procesos de transición desde sistemas autocráticos autoritarios a democracias liberales, llegando a afirmar que no se puede creer que en los procesos como los europeos o americanos, los cambios se hayan basado en situaciones causales, sino que establece un modelo propio desarrollado a partir de casos concretos entre los que destacan: "Los factores que juegan a favor de la estabilidad de una democracia (...) pueden no coincidir con los datores que la han hecho posible (...) La génesis de las democracias liberales no es no social ni geográficamente uniforme (...) Mientras en sus diversas etapas pueden ser cruciales distintos factores" (Requejo Coll ,1990:219).

En base a lo anterior, concluimos que mal se puede establecer de un "patrón genético" de cómo nacen las democracias, pues no sólo éste no es individual, sino que si se quisiese establecer un modelo de transición, por ejemplo la americana, se deberían analizar y coincidir tantos factores como casos analizados, lo cual en Latinoamérica este supuesto no sucede al cien por cien.

Por su parte otros autores, como Lijphart (2006), sostienen que una alternativa a las democracias delegativas son justamente aquellas que presenten mayor benignidad y benevolencia, esto es aquellas que presenten mayor apertura a las mujeres, igualdad política y mayor participación en las elecciones, así como mejores accesos para la participación en la decisión de las políticas públicas, lo cual implicaría que las aspiraciones de los votantes estarían perfectamente reflejadas. Todo esto se entendería al menos con una mayor implicación y mejora en los siguientes cuatro elementos: a) bienestar social; b) protección ambiental; c) justicia penal; $y, d$ ) ayuda exterior. 


\section{LOS RETOS DE LA DEMOCRACIA LATINOAMERICANA Y LOS DERECHOS HUMANOS COMO FACTOR DE COHESIÓN}

El camino que queda por recorrer en la construcción de la democracia en Latinoamérica, no es nada sencillo como se ha señalado anteriormente puesto que si bien es cierto se han superado los primeros retos que supusieron luchar contra los regímenes autoritarios, $\mathrm{y}$ establecer un ambiente (gobernabilidad) en el cual las instituciones del Estado pudiesen desarrollar de cierta manera, para ofrecer así estabilidad y seguridad jurídica en la región.

En la actualidad los problemas que nos podrían aproximar a una crisis en nuestros Estados, son nuevos lo cual exige una respuesta que permita la separación y regulación adecuada de otros tipos de poderes, y que Ferrajoli (2011:45), los caracteriza en cuatro esferas entre:

a) Estado y pueblo.

b) Esfera pública y privada.

c) Fuerzas políticas e instituciones públicas.

d) Poderes mediáticos y libertad de cultura, y de la información.

Recordemos que la construcción del concepto mismo de los Derechos Humanos es posterior a la II Guerra Mundial, razón por la cual el escenario de la posguerra, servirá de referente para que los Estados frente a las agresiones vividas por los regímenes totalitarios impongan unos límites que contribuirían a consolidar aquellas nacientes democracias.

Si bien es cierto, que dentro del mundo bipolar de mediados del siglo XX, el discurso de la amenaza comunista caló de sobremanera en Latinoamérica, puesto que la influencia de Estados Unidos era tal que deseaba imponer su modelo en toda la región; sin embargo, resultó contradictorio cómo durante algunas décadas por el simple hecho de eliminar los "focos" insurgentes, (EEUU) tuvo que aliarse con estructuras de corte militar que establecieron dictaduras, que precisamente en lugar de defender los postulados en defensa de los Derechos Humanos, fueron los que vulneraron los derechos de un conjunto importante de la población.

Consecuencia del hecho antes señalado, reside la importancia de la lucha y la evolución de los Derechos Humanos en el continente, como elemento diferenciador y sobre todo como instrumento a fin de eliminar las inequidades que existían en contra de los grupos sociales y étnicos por parte de un aparato del Estado opresor, que sólo después de más de tres décadas es sancionado por la justicia.

Sin embargo, tras la caída del muro de Berlín, la dinámica internacional cambió de tal modo que en un escenario multipolar, la protección de los Derechos Humanos ya no se centraría en el simple activismo de difusión y control, sino al contrario el camino fue el fortalecimiento de las instituciones gubernamentales, y de la responsabilidad pública, vista desde un doble punto de vista: la primera de manera vertical, esto es por parte de las autoridades frente a los gobernados, y la otra horizontal, por parte de los Estados en la comunidad internacional. (Shattuck, 2004).

La posibilidad de exigir responsabilidades a quienes hubiesen cometido violaciones de los derechos fundamentales de los individuos, sin importar su cargo o posición, fue un elemento que posibilitó la reconciliación y la consolidación democrática de manera positiva en la región.

La construcción de una estructura institucional en el continente favoreció el poder alcanzar mayores niveles de protección de los derechos, de la misma forma que contribuyó con el escenario adecuado para la gobernabilidad democrática, pues atenuó y mejoró las posibles tensiones entre política y ciudadanía. (Shattuck, 2004:357). 
El elemento común que de manera adecuada los países latinoamericanos han sabido utilizar como integrador en la construcción de su democracia, ha sido el respeto de los derechos humanos, vistos como un todo que evite categorizaciones innecesarias, y que permitan ser verdaderamente ese contrapoder social a través de reglas a fin de evitar la imposición de los poderes fácticos de la mayoría.

Justamente una de las maneras para medir el grado de legitimidad de un Estado de Derecho tal como lo señala el profesor Ferrajoli, se hace a través de "(...) el grado de efectividad y con el grado de inefectividad de las garantías de los derechos constitucionalmente establecidos en él" (Ferrajoli, 2011:43)

\section{ALGUNAS REFLEXIONES FINALES}

Antes de establecer las líneas sobre el futuro de la democracia, merece la pena tener presente el análisis de Bobbio, quien cuando se le pregunta sobre un diagnóstico de futuro, respondía que hace falta aprender de los grandes filósofos, Hegel y Weber, quienes cuando se les preguntaba por estos temas, sostenían que el oficio de profeta es peligroso, razón por la cual solamente esbozaremos algunas ideas que creemos serán las que inspiren los devenires en el plano regional.

Los instrumentos jurídicos a nivel nacional (Constituciones) e internacional (Tratados Internacionales), ofrecen un amplio catálogo para la protección de los derechos de los individuos, los cuales se encuentran a su disposición como forma de establecer límites al poder que desde el Estado se ejerce; sin embargo, dada la estructura y sobre todo la realidad de los gobiernos a nivel latinoamericano, como lo hemos estudiado en el presente artículo, es clara la confusión que se presenta en el caso de los presidentes cuando pretenden traspasar la delegación otorgada por los ciudadanos en las urnas con su voto para cumplir un mandato determinado, frente a lo que en realidad pasa que el sufragio se convierte en una carta en blanco y, en un poder sin límites, que como hemos visto puede generar serios riesgos para los regímenes democráticos y alterar la estructura del Estado de Derecho.

Es claro que el papel de los presidentes de la República, residen en un mandato determinado, al cual deben de ceñirse, y que tienen como límite los derechos fundamentales de los individuos, catálogos que han sido constitucionalizados en las Cartas Magnas de los distintos Estados y que tienen como principio la progresividad de estos derechos, esto es, que ningún proceso posterior puede retrotraer o limitar su aplicación, incluso, valga la pena insistir, frente a aquellas mayorías o procesos plebiscitarios, pues como ya se ha señalado podrían acarrear las conocidas tiranías de las mayorías, figuras que salen de las estructuras democráticas.

Pero qué hacer en una región, en la cual se nos ha inculcado de manera errónea que el voto es el único sinónimo de democracia, y en su nombre se puede hacer cualquier cosa, lo cual lleva a que la limitación, ampliación o denegación de un derecho, cuando se encuentra en duda, la única solución sea someterlo a una Consulta o Referéndum Popular.

El propio Estado Constitucional de Derecho, ha diseñado una estructura que permite que sean instituciones sólidas, constitucionalmente definidas las cuales se encarguen de dirimir, interpretar y dar contenido a los derechos; y dichas funciones las cumplen en cada uno de los países estudiados, tanto las Cortes Nacionales de Justicia así como sus Cortes Constitucionales, respectivamente. 
Hemos visto también conforme lo plantea Sartori, que las diferencias sustanciales que se encuentran entre la democracia antigua y la contemporánea, radican en que en la segunda se busca un sistema adecuado que permita ejercer el control y la limitación del poder, mientras que en la democracia antigua existió la posibilidad de ejercer de manera directa la toma de decisiones por el propio ciudadano, lo cual al parecer en la actualidad, lo vemos como un baluarte que en la práctica está lejos de funcionar, es por ello que aparecen formas de participación ciudadana que colaboren en el ejercicio del poder pero que no sean los únicos.

Dentro de los modelos estudiados en este artículo el elemento denominador reside en la fuerza que los constituyentes otorgaron a la ciudadanía en la toma de decisiones, para lo cual las herramientas apropiadas constituyen los procesos de participación ciudadanía y control social, los cuales hasta la fecha no han sido activados al cien por cien, quedando esta interesante propuesta en parte de un ideario político partidista. Es pues hora de que mujeres y hombres se apropien de lo público, entendido como la esfera propicia para la satisfacción de las necesidades de los ciudadanos, a través de procesos de educación en valores democráticos, pero sobre todo en la promoción y protección de los Derechos Humanos; sólo de esta manera la región no mirará atrás hacia los regímenes autoritarios de finales del siglo $\mathrm{XX}$, y se encaminará a la consolidación de una democracia participativa, incluyente donde el ser humano sea el protagonista.

\section{BIBLIOGRAFÍA}

ABELlÁn, J. (2011). Democracia: Conceptos Políticos Fundamentales. Madrid: Alianza.

BERDUGO, I. y RIVERO, R. (eds.) (2003). El Estado de Derecho Latinoamericano. Integración Económica y Seguridad Jurídica en Iberoamérica. Salamanca: Ediciones Universidad de Salamanca. BOBBIO, N. (1985). El futuro de la democracia. Barcelona: Plaza \& Janes.

CHUECA, R. (1993). La regla y el principio de la mayoría. Madrid: Centro de Estudios Constitucionales.

DÍAZ, E. (2010). El Estado de Derecho y Sociedad Democrática. Madrid: Taurus.

ESCOBAR, G. y GUEDÁN, M. (2005). Democracia e Instituciones en América Latina. Madrid: Dykinson.

FISHKIN, J. (1995). Democracia y deliberación. Barcelona: Ariel.

FERRAJOLI, L. (1999). Derechos y garantías. La ley del más débil. Madrid: Trotta.

FERRAJOLI, L. (2006). Una discusión sobre Derecho y Democracia. Madrid: Trotta.

FERRAJOLI, L. (2011). Poderes salvajes. La crisis de la democracia constitucional. Madrid: Trotta.

HELD, J. (2008). Modelos de democracia. Madrid: Alianza.

LECHNER, N. (1990). Los patios interiores de la democracia. Subjetividad y Política. Santiago: Fondo de Cultura Económica.

LINZ, J. (1987). La quiebra de las democracias. Madrid: Alianza.

LINZ, J. (1998). La crisis del Presidencialismo. Vol II: El caso de Latinoamérica. Madrid: Alianza.

LIJPHART, A. (2006). Modelos de democracia. Formas de gobierno y resultados en treinta y seis países. Barcelona: Ariel.

GALlEGO ANABITARTE, A. (2009). Poder y Derecho del Antiguo Régimen al Estado Constitucional en España. Siglos XVIII a XIX: conceptos, instituciones y estructuras administrativas en el nacimiento del Estado Moderno. Madrid: Marcial Pons.

GONZÁLEZ, J. y QUESADA, F. (coords.) (1992). Teorías de la Democracia. Barcelona: Anthropos.

MARINA, J.A. y VÁLGOMA, M. de (2001). La lucha por la dignidad. Teoría de la felicidad política. Barcelona: Círculo de Lectores.

MAINWARING, S. y VALENZUELA, A. (1998). Politics, Society, and Democracy. Latin America. Colorado, USA: Westview Press. 
MARTÍNEZ, A. (2013). Los movimientos políticos como opción a la "partidocracia" en Ecuador. El predominio de estas nuevas agrupaciones inscritas en el Consejo Nacional Electoral. Madrid: Publicaciones, Instituto Complutense de Ciencia de la Administración.

MARTÍNEZ, B. E. (2012). "Cortes Supremas y candidaturas presidenciales en Centroamérica", en Revista de Estudios Políticos, 158: 165-206.

MENÉNDEZ ALZAMORA, M. (ed.) (2009). Participación y representación política. Valencia: Tirant lo Blanch.

MURILLO, G. y PIZANO, L. (1999). "La democracia participativa en la encrucijada: El caso colombiano". En S. Sosnowoski y R. Patiño (comps.) Una cultura para la democracia en América Latina. México DF: Fondo de Cultura Económica.

O’DONNELL, G. (1994). "La democracia delegativa”, en Journal of Democracy, Vol. 5, 1:55-69.

OLMEDA, J. (comp.) (2005). Democracias frágiles. Las relaciones civiles-militares en el mundo iberoamericano. Valencia: Tirant lo Blanch.

REQUEJO COLL, F. (1990). Las democracias. Democracia antigua, democracia liberal y Estado de Bienestar. Barcelona: Ariel.

REY, J. L. (2012). La democracia amenazada. Alcalá de Henares: Universidad de Alcalá.

ROITMAN, M. (2003). Las razones de la democracia en América Latina. Madrid: Sequitur.

SARTORI, G. (1993). La democracia después del comunismo. Madrid: Alianza.

SARTORI, G. (2009). La democracia en 30 lecciones. Madrid: Taurus.

SHATTUCK, J. (2004). "Los derechos humanos y la democracia en la práctica: el desafío de la responsabilidad". En H. Hongju y R. Slye (comps.) Democracia deliberativa y derechos humanos. Barcelona: Gedisa.

TOCQUEVILLE, A. (1969). La democracia en América. Madrid: Guadarrama.

TOURAINE, A. (1994). ¿Qué es la democracia? Madrid: Temas de Hoy.

VINTRÓ CASTELL, J. (1987). "La Constitución nicaragüense y la tradición liberal democrática", en Revista Parlamentaria, 3: 71-88. 


\section{Breve currículo:}

\section{Andrés Martínez Moscoso}

Abogado de los Tribunales de Justicia de la República del Ecuador. (Universidad del Azuay) y Doctorando en Estudios Políticos y Constitucionales por la Universidad de Alicante. Condecoración "Honorato Vásquez", al mejor egresado de la Facultad de Ciencias Jurídicas. Máster Universitario Oficial en Protección en Derechos Humanos (Universidad de Alcalá). Máster en Liderazgo Político y Dirección de Instituciones Político-Administrativas (Universidad de Alicante). Especialista en Derecho Constitucional (Universidad del Azuay). Miembro investigador del Observatorio Lucentino de Administración y Políticas Públicas Comparadas del Área de Ciencia Política y de la Administración de la Universidad de Alicante, estudios que los realiza gracias a una beca de excelencia del gobierno del Ecuador. Docente e investigador universitario desde 2007 (Universidad del Azuay/Universidad de Cuenca).

\section{Manuel Francisco Ruiz Guerrero}

Profesor titular de la Universidad Nacional Autónoma de Nicaragua Unan-León y doctorando en Estudios Políticos Constitucionales por la Universidad de Alicante. Máster en Instituciones Políticas por la Universidad de Santiago de Compostela y Especialista en Derechos Humanos, Democracia y Globalización por la Universidad Oberta de Cataluña. 